\title{
PolítiCAS DE EDUCAÇÃo ESPECIAL: ANÁlISE dO PLANO DE EDUCA- ÇÃO (2015 - 2025) E DIRETRIZES DA EDUCAÇÃO ESPECIAL (2012) DE MACAPÁ-AP
}

\author{
SPECIAL EDUCATION POLICIES: ANALYSIS OF THE EDUCATION \\ PLAN AND GUIDELINES FOR MACAPÁ-AP SPECIAL EDUCATION
}

Marcia Maria dos Santos Mestranda pelo Programa de Pós-Graduação em Educação pela Universidade Federal do Amapá. Amapá - AP - Brasil marcia_m_santos@hotmail.com

\section{Maria do Carmo Lobato da Silva}

Doutoranda em Educação Especial pelo Programa de Pós-Graduação em Educação Especial na Universidade Federal de São Carlos. Docente da Universidade Federal do Amapá. Amapá - AP - Brasil carmo.lobato@yahoo.com.br

Ilma de Andrade Barleta Doutora em Educação pela Universidade Federal do Pará. Docente da Universidade Federal do Amapá. Amapá - AP - Brasil ilmabarleta@bol.com.br

Resumo: Este artigo analisa a concepção de educação inclusiva a partir das metas para Educação Especial no Plano Municipal de Educação (2015-2025) e nas Diretrizes para a Educação Especial (2012) implementados em Macapá, com foco principal na análise dos compromissos assumidos para o gerenciamento das ações em torno da educação dos alunos com deficiência intelectual. O estudo se configurou como pesquisa documental, de abordagem qualitativa à luz do materialismo histórico, que considera o processo dos fenômenos estudados e como eles se

Cadernos de Pós-graduação, São Paulo, v. 17, n. 2, p. 197-221, jul./dez. 2018. 
constituem na concretude das políticas educacionais neoliberais. Para tanto, fez-se uso da análise do discurso, pautada na concepção de Bakhtin (2006) e Fairclough (2001). A metodologia baseou-se na análise dos documentos: 1) Plano Municipal de Educação (2015-2025) com ênfase nas metas para educação especial; 2) Diretrizes para Educação Especial (2012), a fim de captar até que ponto os discursos apresentados, refletem o processo de inclusão dos alunos com deficiência intelectual no Município de Macapá. Os resultados indicaram uma educação que está distante de se efetivar de forma plena, tanto pela incompreensão de suas concepções e fundamentos, quanto pela escassez de recursos para a manutenção da Educação Especial. Portanto, o discurso dos documentos sinaliza que a política de inclusão das pessoas com deficiência, em caráter local, segue os preceitos da política geral consubstanciada no modelo neoliberal com enfoque clínico conservador da deficiência.

Palavras-chave: Alunos com deficiência intelectual. Concepção de deficiência. Política municipal de educação especial.

\begin{abstract}
This article analyzes the conception of inclusive education from the goals for Special Education in the Municipal Education Plan (2015-2025) and in the Guidelines for Special Education (2012) implemented in Macapá, focusing on the analysis of the commitments assumed for the management of actions around the education of students with intellectual disabilities. The study was configured as a documentary research with a qualitative approach under the light of historical materialism, that considers the process of the studied phenomena and how they constitute the concreteness of neoliberal educational policies. For this purpose, it was used the speech analysis based on Bakhtin (2006) and Fairclough (2016) ideas. The methodology was analyzed the documents: 1) Municipal Education Plan (2015-2025), with emphasis on the goals for special education; 2) Guidelines for Special Education (2012), to capture whither the speeches presented reflects the process of inclusion of students with intellectual disabilities in Macapá. The results indicated an inclusive education far from being fully effective, due to the lack of understanding of its conceptions and foundations, as well as the scarcity of resources to the maintenance of Special Education. Therefore, the discourse of the documents indicates that the inclusion policy of people with disabilities, in a local character, follow the precepts of general policy embodied in the neoliberal model with a conservative clinical approach to disability.
\end{abstract}

Keywords: Students with intellectual disabilities. Deficiency conception. Special education policy.

Cadernos de Pós-graduação, São Paulo, v. 17, n. 2, p. 197-221, jul./dez. 2018. 


\section{Introdução}

$$
\begin{aligned}
& \text { educação de pessoas com deficiência intelectual, na atual conjuntura, } \\
& \text { está consubstanciada por concepções e determinações de políticas ofici- }
\end{aligned}
$$
ais de Educação Especial e Inclusiva. Tais políticas se materializam por meio de discursos efetivados nas Legislações, Decretos, Diretrizes e Planos Educacionais de Governos: Federal, Estadual ou Municipal (KASSAR, 2011). Esta pesquisa propõe reflexões sobre a concepção de projetos em disputa de educação inclusiva a partir da análise das metas para a educação especial do Plano Municipal de Educação (2015-2025) e das Diretrizes para a Educação Especial (2012) implementadas no Município de Macapá, tomando como foco principal a análise dos compromissos assumidos para o gerenciamento das ações em torno da educação dos alunos com deficiência intelectual.

Trinta anos depois da criação da Constituição Federal de 1988 que incorporou inúmeros direitos aos cidadãos, fruto de lutas populares e disputas de projetos sociais e educacionais, dentre eles, a garantida obrigatoriedade do direito à educação para pessoas com deficiência (BRASIL, 1988), o acesso ao Ensino Regular se tornou o slogan principal das políticas na perspectiva inclusiva. O discurso assegurava que as crianças com deficiência estavam ingressando na escola na idade certa e inseridas numa classe regular com apoio do Atendimento Educacional Especializado (AEE), ofertado na maioria das escolas municipais. O serviço do AEE é reafirmado com a política da Educação Especial na Perspectiva Inclusiva, que o pontua como direito ao acesso desde a educação Infantil, perpassando os demais níveis de ensino (BRASIL, 2010).

Ocorre que, apenas a garantia do acesso físico não provoca rupturas nos espaços escolares, pois dentro de um projeto de inclusão que compreende uma educação com qualidade, igualdade de condições de acesso, acessibilidade e permanência é fundamental que sejam atendidas todas as necessidades dos alunos. Não obstante a isso, a 
Políticas dE EDUCAÇÃo ESPECIAL: ANÁLISE DO PLANO DE EDUCAÇÃo (2015 - 2025) E DIRETRIZES DA EDUCAÇÃO ESPECIAL (2012) DE MACAPÁ-AP

história da educação especial, segundo Kassar (2009), aponta vários exemplos de descasos com a população brasileira e os momentos de avanços legais nesse campo foram também guiados pela lógica econômica, do mercado e do lucro.

Muitos docentes, pais e estudiosos da área da Educação Especial estão engajados na luta por melhores condições de ensino e aprendizagem, com perspectivas para a concretude dos discursos contidos nas políticas educacionais. Para Kassar, de Oliveira e da Silva (2007) não se deve tratar o processo de inclusão de forma abstrata, nem negligenciar seu papel como espaço privilegiado de acesso ao saber. Pois é desta forma que as políticas estão sendo gestadas e implementadas em todo país.

Por isso, os estudos a cerca da temática sobre as políticas educacionais voltados para a Educação Especial têm sido cada vez mais explorados, com o intuito de compreender como é instituída a inclusão dos alunos em diferentes níveis de ensino. Sendo assim, é preciso ter a clareza que esse processo envolve a entrada na escola, a permanência e a aprendizagem com qualidade.

Desta forma, a pesquisa foi realizada com intuito de analisar os discursos veiculados no Plano Municipal de Educação (2015-2025) e das Diretrizes para a Educação Especial (2012) que norteiam as políticas educacionais do município de Macapá/AP. Caracterizando-se como documental, de abordagem qualitativa à luz do materialismo histórico, apoiada na análise do discurso.

Nos procedimentos metodológicos foram feitos recortes dos documentos, com foco na análise da meta 4 do Plano Municipal de Educação (2015-2025), que compreende o conceito e concepção da Educação Especial e restringindo-se as estratégias 4.1, que trata da contabilização das matriculas de estudantes da rede pública que recebem o atendimento educacional especializado (AEE) de forma complementar ou suplementar; a estratégia 4.3 trata da implementação e manutenção das Salas de Recursos Multifuncionais (SRM) em parceria com o Governo Federal; e, para finalizar, a estratégia 
4.26 que trata do quantitativo de alunos com deficiência em sala de aula. Já nas Diretrizes municipais para a Educação Especial (2012), buscou-se compreender a concepção de educação e inclusão voltada para os alunos com deficiência intelectual, em que conceitos e características se fundamentam.

Para Shiroma, Campos e Garcia (2005), compreender e intervir criticamente nos processos de inclusão escolar dos alunos com deficiência, à luz das políticas públicas, faz-se necessário investigar como a ideologia, a lógica e a racionalidade que apoiam os textos das políticas educacionais, dentro de um contexto de reformas articulam-se com os interesses, valores, perspectivas dos sujeitos que utilizam e realizam as mudanças sociais a partir das políticas em curso. Para as autoras, neste contexto de reforma educacional é importante perceber:

Quais os caminhos trilhados na busca de legitimação das reformas? Se entendermos discurso como expressão e diretriz de práticas sociais, indagamos: como seriam eles capazes de transformar as práticas que ocorrem nas instituições educacionais? Como chegam a alterar a cultura das organizações escolares, as práticas e relações sociais que se travam em seu interior? E como poderemos construir novas lentes para interpretar os textos da reforma, compreender e intervir criticamente nos rumos desta política? (SHIROMA; CAMPOS; GARCIA, 2005. p. 430).

Neste sentido há uma preocupação em considerar o processo dos fenômenos estudados e como ele se constitui. É na tentativa de estudar as políticas educacionais para a educação especial que se tenta analisar a concretude dos pressupostos e determinações contidos nos registros de documentos oficiais para as pessoas com deficiência. Corrêa e Kassar (2009) analisam este fenômeno como parte de uma totalidade, acreditando ser necessária a compreensão da concepção de movimento contraditório inerente à própria história.

Sendo assim, a gestão da Educação Especial na esfera municipal vem se configurando como processo de descentralização que desde a Constituição Federal de 1988 
Políticas de EDUCAÇÃo ESPECIAL: ANÁLISE DO PLANO DE EDUCAÇão (2015 - 2025) E DIRETRIZES DA EDUCAÇÃO ESPECIAL (2012) DE MACAPÁ-AP

possibilitou aos municípios maior autonomia relativa na formulação de políticas educacionais, principalmente para o Ensino Infantil e Fundamental (SOUZA; FARIA, 2004). Com isso, é perceptível atos puramente contraditórios, quando delega ao município poderes que muitas vezes não consegue cumprir devido à injusta divisão de responsabilidades provocada pelo Governo Federal, no sentido de centralizar os recursos e atribuir o mínimo aos municípios da federação.

\section{$2 \mathrm{O}$ processo de municipalização no contexto das políticas de educação especial}

$\mathrm{Na}$ atual conjuntura política, econômica, administrativa e social os processos de reforma apontam para a descentralização da educação pela via da municipalização e se efetiva a partir de um longo período de regime autoritário ao qual predominou políticas de desinvestimentos da Educação Básica (SOUZA, FARIA, 2004).

Este cenário se configura em processos históricos que marcam a trajetória da educação no Brasil, modificando as formas de administrar o Estado no sentido de descentralizar as estruturas gerenciais na esfera pública. Neste viés, Corrêa e Kassar (2009) colaboram na caracterização deste processo:

O Brasil da década de 1980 foi marcado por um processo de redemocratização, após 20 anos de ditadura militar. Esse período é o contexto das lutas travadas na elaboração da Constituição Federal de 1988, que produz um novo estatuto jurídico para o país. Pode-se afirmar que, contando com o envolvimento da sociedade civil organizada, essa Constituição caracteriza-se por uma ênfase nos direitos sociais. (CORRÊA; KASSAR, 2009, p. 02).

Com isso, a educação das pessoas com deficiência agrega-se a este contexto, também resultante das lutas de pais, educadores e os próprios atores mencionados nas políticas que determinam seu desenvolvimento educacional. Não se pode negar a ênfase 
dada aos direitos sociais na Constituição Federal de 1988, que sob a lógica de desenvolvimento do Estado coloca no bojo de suas políticas a educação como “direito público e subjetivo" (BRASIL, 1988, art. 208).

Neste sentido, o processo de municipalização ganha força a partir da criação da União Nacional dos Dirigentes de Educação, (UNDIME) em 1986, que mesmo sem ter este objetivo começa a se posicionar a favor de uma maior participação do município nos processos educacionais, exigindo descentralização nas ações do poder público (CORRÊEA; KASSAR, 2009).

Sendo assim, em se tratando do que consta na Constituição Federal de 1988 no seu Artigo 211, elencado o regime de colaboração entre a União, Estados, Municípios e o Distrito Federal, hoje em consonância com as emendas n ${ }^{\circ} 14 / 1996, n^{\circ} 53 / 2006$ e $\mathrm{n}^{\mathrm{o}} 59 / 2009$ que determina:

211- \ $1^{\circ}$ A União organizará o sistema federal de ensino e o dos Territórios, financiará as instituições de ensino públicas federais e exercerá, em matéria educacional, função redistributiva e supletiva, de forma a garantir equalização de oportunidades educacionais e padrão mínimo de qualidade do ensino mediante assistência técnica e financeira aos Estados, ao Distrito Federal e aos Municípios; (Redação dada pela Emenda Constitucional no 14, de 1996).

$\S 2^{\circ}$ Os Municípios atuarão prioritariamente no ensino fundamental e na educação infantil. (Redação dada pela Emenda Constitucional $\mathrm{n}^{\mathrm{o}}$ 14, de 1996).

$\S 3^{\circ}$ Os Estados e o Distrito Federal atuarão prioritariamente no ensino fundamental e médio. (Incluído pela Emenda Constitucional ${ }^{\circ}$ 14, de 1996).

$\int 4^{\circ} \mathrm{Na}$ organização de seus sistemas de ensino, os Estados e os Municípios definirão formas de colaboração, de modo a assegurar a universalização do ensino obrigatório. (Incluído pela Emenda Constitucional $\mathrm{n}^{\circ} 14$, de 1996).

$\int 4^{\circ} \mathrm{Na}$ organização de seus sistemas de ensino, a União, os Estados, o Distrito Federal e os Municípios definirão formas de colaboração, de modo a assegurar a universalização do ensino obrigatório. (Redação dada pela Emenda Constitucional n 59, de 2009). 
Políticas de EDUCAÇão especial: ANÁlise do PLANO DE EDUCAÇÃo (2015 - 2025) E DIRETRIZES DA EDUCAÇÃO ESPECIAL (2012) DE MACAPÁ-AP

$\int 5^{\circ} \mathrm{A}$ educação básica pública atenderá prioritariamente ao ensino regular. (Incluído pela Emenda Constitucional $n^{\circ}$ 53, de 2006). (BRASIL, 1988).

É importante destacar que é a partir do artigo 211 da Constituição Federal de 1988 que realmente se efetiva a organização dos sistemas de ensino pelo então chamado regime de colaboração. Porém, com o passar dos anos este documento passa a se fragmentar em várias Emendas Constitucionais (EC), como é o caso da EC no 14/1996, da EC no 53/2006 e da EC n 59/2009 que vão dar nova redação ao artigo da CF/1988 (SOUZA; FARIA, 2004).

Desta forma, a partir do conhecimento, reconhecimento e compreensão dos textos das legislações que legitimam as políticas educacionais, percebe-se necessidade de aprender decifrar os textos para poder compreender as políticas. No caso acima (art. 211), as EC assumem um papel de camuflar o verdadeiro sentido em suas narrativas. Como exemplo, pode-se citar a EC no 14/ 1996 da Constituição Federal, no seu Art. $1^{\circ}$ acrescenta no inciso VII do Art. 34 a alínea "e” dizendo que: "aplicação do mínimo exigida da receita resultante dos impostos Estaduais compreendida a proveniente de transferência, na manutenção e desenvolvimento do ensino” (BRASIL, 1996).

Outra EC que merece análise é a de no 59/2009 da CF que acrescenta ao art.76 do ato das disposições constitucionais transitórias o inciso $3^{\circ}$ constando que se deve reduzir anualmente, a partir de 2009, o percentual da desvinculação das Receitas da União incidentes sobre os recursos destinados à manutenção e desenvolvimento do ensino de que trata o art. 212 da CF/1988. Torna obrigatório o ensino na faixa etária de quatro a dezessete anos e amplia a abrangência dos programas suplementares para todas as etapas da Educação Básica e dá outras providências (BRASIL, 2009).

Cabe aqui, segundo Souza e Faria (2004) evidenciar que os municípios assumem as políticas que gerenciam a educação básica que antes apontavam para decisões compartilhadas entre os sistemas de ensino iguais e autônomos entre os entes federados, 
agora rompe com os anseios da sociedade civil de uma educação de qualidade e inclusiva para todos a partir das emendas constitucionais que desqualificam o teor dos artigos constitucionais.

Sendo assim, cabe o questionamento se realmente o município tem condições econômicas, políticas e sociais de cumprir com os compromissos assumidos nas ações dos Planos e Diretrizes municipais no que diz respeito aos alunos com deficiência intelectual. Considerando que os mesmos, assim como qualquer aluno em processo de aprendizagem, necessitam de acesso não somente aos espaços escolares, mas também de todo um aparato pedagógico e estrutural que favoreça o seu desenvolvimento de forma plena.

Por mais que, no âmbito das políticas educacionais de caráter inclusivo ancoradas em marcos legais que proclamam uma educação de qualidade, como é o caso do Movimento de Educação para Todos com as conferências ocorridas a partir dos anos 1990: Conferencia Mundial de Educação para Todos, ocorrida em Jontien, na Tailândia em 1990, aprovada por representantes de mais de cem países e Organizações Não Governamentais (ONG’s), cujo propósito foi aumentar a oferta da Educação Básica para a população mundial no prazo de 10 anos, seus princípios evidenciaram que este nível de ensino seria satisfatório às necessidades básicas da aprendizagem (RABELO; JIMENEZ; SEGUNDO, 2015).

Continuamente a Conferência de Nova Delhi (1993); a Declaração de Salamanca (1994); Dakar (2000); Constituição Federal de 1988; a Lei de Diretrizes e Bases da Educação Nacional (LDBEN 9394/1996), entre outros que carregam em seus escritos, perspectivas de universalizar o saber, priorizar a qualidade no ensino para a população excluída, sob a prospecção de incluir a todos na escola, inclusive as pessoas com deficiência intelectual. É importante pontuar que esta Educação não pode ser analisada isoladamente dos contextos social, político-ideológico e econômico, partindo do 
Políticas dE EDUCAÇÃo ESPECIAL: ANÁLISE DO PLANO DE EDUCAÇÃo (2015 - 2025) E DIRETRIZES DA EDUCAÇÃO ESPECIAL (2012) DE MACAPÁ-AP

princípio que a educação das pessoas com deficiência, também está fortemente marcada pelos interesses hegemônicos do capital (SILVA; OLIVEIRA, 2015).

O discurso destas políticas, segundo Rabelo, Jimenez e Segundo (2015) carrega a promoção de conferências com instrumentos nacionais e internacionais, que se configuram como marco estratégico no sentido de proclamar um novo papel que a Educação Básica deve desempenhar: "provocar a sustentabilidade dos países envolvidos com a agenda neoliberal" (RABELO; JIMENEZ; SEGUNDO, 2015, p. 14). Assim, a partir da proposição de que com o mínimo se faz mais se vêm implantando as políticas de inclusão no município.

Desta forma, faz-se necessário evidenciar o papel do Estado na atual conjuntura neoliberal e seu descompromisso com a escolarização das crianças com deficiência, onde a ação educativa assim como outros direitos sociais, passa a ser considerada como "serviço" que pode ser prestado pelos setores privados da sociedade por meio de um contrato de gestão estabelecido com o Estado. O município como ente federado também segue a mesma regra, no sentido de estabelecer parcerias entre o público e o privado.

O espaço do público se perde para o privado quando o Estado se retira da responsabilidade do seu compromisso com o financiamento do sistema educacional, seja ele regular ou especial. Com esse propósito, nos estudos de Borowsky (2013), Januzzi (2006), Garcia (2004), Peroni (2009), Farenzena e Machado (2006) e Gil et al (2010) sustentam as discussões que vêm sendo realizadas no âmbito do sistema de ensino público e o privado na Educação Especial, apontando que nesta trajetória o setor privado se sobrepõe ao público. Um exemplo claro disso se remete aos casos de alunos com sérios comprometimentos de natureza neurológica (mental ou intelectual) ou aqueles que não se enquadram na atual política de Educação Inclusiva, aqueles que a escola regular não consegue atender estão em escolas especiais na rede privada, com 
um percentual de matrículas de 65\% no período de 2007 a 2010 em instituições privadas. Sendo estas, mantidas com recursos do setor público, fortalecendo o sistema de parcerias (BOROWSKY, 2013).

\section{Resultados e discussão}

O Plano de Educação Municipal de Macapá, instituído pela Lei n 2.178/2015, aprovado para o decênio de 2015 a 2025, constituiu-se de 20 metas. Para este estudo, fez-se um recorte da meta 4.0 e dentre as trinta e uma estratégias destinadas à Educação Especial com propósito de serem efetivadas num período de dez anos, focou-se em apenas três (4.1; 4.3 e 4.26) no sentido de analisar a concretude das determinações contidas no documento tendo como direcionamento os alunos com deficiência intelectual.

Nestas estratégias, há que se contabilizar e enfatizar os vocábulos com maior predominância: "promover e garantir" (MACAPÁ, 2015, p.12-16). Tais vocábulos, de acordo os estudos sobre Educação Especial na atualidade se tornam imperativos, no sentido de apenas compor os textos das políticas públicas, que no caso aqui são os Planos e Diretrizes Municipais para a Educação Especial. Logo, a concretude de seus objetivos está fora da compreensão de serem alcançados. Pois, as políticas de inclusão no município de Macapá também incorporaram o discurso neoliberal, que tenta promover uma inclusão aos moldes da hegemonia do capital.

Dessa forma ocorre o discurso hegemônico nas diretrizes da Educação Especial de Macapá (2012), particularmente ao analisar as concepções e fundamentos do projeto de educação inclusiva para os alunos com deficiência intelectual, observando os modelos de educação em que se concebe a educação destes no município em estudo. Pois é deste lócus que se inicia toda a estruturação e sistematização da vida escolar de seus munícipes. 


\subsection{Os alunos com deficiência intelectual e os (des) compromissos assumidos nas metas do Plano de Educação Municipal}

As pessoas com deficiência intelectual, de acordo com a Política Nacional de Educação Especial na Perspectiva Inclusiva (BRASIL, 2010), conceituam-se como "aquelas que têm impedimentos de longo prazo, de natureza física, mental ou sensorial que, em interação com diversas barreiras, podem ter restringida sua participação plena e efetiva na escola e na sociedade" (BRASIL, 2010, p. 21). Desta forma, as políticas de inclusão devem se organizar no atendimento as necessidades específicas de seu alunado. Por isso que o poder público municipal responsável por tais ações, vem organizar o seu sistema de ensino traçando planos para um determinado fim nos diversos setores e modalidades educacionais. Assim, a quarta meta corresponde às determinações para a educação especial propondo que:

Universalizar, para a população de quatro a dezessete anos com deficiência, transtornos globais do desenvolvimento e altas habilidades/superdotação, o acesso à Educação Básica e ao atendimento educacional especializado preferencialmente na rede regular de ensino, com garantia de sistema educacional inclusivo, de salas de Recursos Multifuncionais (SRM) e de classes, escolas ou serviços especializados, públicos ou conveniados (MACAPÁ, 2015, p. 12).

A partir desta meta, percebe-se que as determinações apresentadas no Plano de Educação Municipal não se configuram prontamente aplicáveis, pois universalizar o acesso a educação básica e ao AEE, preferencialmente na rede regular dentro de uma análise do discurso significa a não obrigatoriedade do ensino inclusivo nas escolas públicas. Também, o movimento do governo Federal tem sido de instalação de salas de recursos multifuncionais nos municípios que aderiram a esta política, apontando a tendência da educação brasileira, como uma proposta inclusiva, efetivando o movimento de contingências econômicas (KASSAR, 2009). Segundo Shiroma, Campos e Garcia (2005) a implementação destas políticas "exige que sejam traduzidas, interpretadas, 
adaptadas de acordo com as vicissitudes e os jogos políticos que configuram o campo da Educação" (p. 430).

É preciso compreender a racionalidade nas informações deste documento, que muitas vezes se apresentam na contradição dos textos das políticas, onde oferecem medidas que aparentam ir em direção contrária ao que propõem (SHIROMA; CAMPOS; GARCIA, 2005).

Neste caso, apenas expandir a matrícula e implantar SRM não garante a materialidade da escola e ensino concretamente inclusivo. Para que aconteçam mudanças na implementação das políticas inclusivas, faz necessário um estudo e uma compreensão maior na interpretação de conceitos, vocábulos e teorias que se apresentam no corpo dos textos das políticas oficiais. Para além disso, é necessário reconfigurar o papel político do Estado frente aos direitos e serviços públicos.

Na estratégia 4.1 do referido Plano de Educação Municipal, são abordados os recursos para a Educação Especial, destacando que há uma necessidade de contabilizar o quantitativo de alunos conforme registro do censo escolar para o controle dos recursos do Fundo de Manutenção e Desenvolvimento da Educação Básica e Valorização do Magistério (FUNDEB), (MACAPÁ, 2015).

Considera-se importante enfatizar a necessidade de aprofundamento e esclarecimento sobre os recursos destinados para a Educação Especial, sobre a forma de detalhamento destes recursos e como eles chegam à sala de alunos com deficiência intelectual. Também não é possível negar a influência de instituições não públicas que aos poucos vão tomando os espaços das escolas públicas. Neste caso, surgem as seguintes questões: Quais as implicações da contabilização do quantitativo no censo escolar para o ensino dos alunos com deficiência? Para quê e para quem servirá este controle dos recursos do FUNDEB? Esses são questionamentos para reflexão, visto que ainda carecem de esclarecimento por parte do documento. 
Políticas dE EDUCAÇÃo ESPECIAL: ANÁLISE DO PLANO DE EDUCAÇÃo (2015 - 2025) E DIRETRIZES DA EDUCAÇÃO ESPECIAL (2012) DE MACAPÁ-AP

Neste sentido as políticas de inclusão no contexto brasileiro que desde a década de 1990, gestadas sob a égide neoliberal enviesam a perspectiva do desenvolvimento humano como forma de minimizar ou silenciar a exclusão dos alunos com deficiência ao longo da história, com o "discurso humanitário de garantia de direitos humanos" (SOUZA; DAINEZ; MAGIOLINO, 2015, p. 32). Com isso, a educação dos alunos, público alvo da educação especial ${ }^{1}$, deve acontecer em salas de aula do ensino regular, com apoio da Educação Especial, realizada pelo Atendimento Educacional Especializado de forma suplementar ou complementar no contra turno do ensino regular (BRASIL, 2010). É lógico, que estas Diretrizes protagonizam a atribuição oferecidas a Educação Escolar, no sentido de provocar a sustentabilidade econômica dos países compromissados com a agenda neoliberal (RABELO; JIMENEZ; SEGUNDO, 2015).

Os municípios brasileiros são os primeiros a receber tal alunado a partir dos acordos realizados com a União e os Estados, com o compromisso de construir, estruturar e implementar políticas, planos e diretrizes no sentido de promover o desenvolvimento humano destes alunos na modalidade de Ensino Fundamental, que é a base de toda a educação. É questionado se realmente as metas e estratégias destes documentos são capazes de atender as necessidades básicas para provocar o aprendizado.

Para responder tal questionamento, apresenta-se a estratégia 4.3 que tem a pretensão de:

Implantar e manter ao longo do PME, em parceria com o Governo Federal, financiamento para construção e estruturação das Salas de Recursos Multifuncionais (SRM), em 100\% das escolas municipais, com os recursos tecnológicos que atendam à necessidade de alunos com necessidades especiais, bem como garantir a formação continuada de docentes para o AEE, tanto nas escolas urbanas quanto nas do campo, voltadas as populações de assentamentos, extrativistas, indígenas, negras, quilombolas e ribeirinhas (MACAPÁ, 2012, p. 12). 
Nesta direção, vale destacar o discurso de realizar uma tarefa em percentuais máximos, no caso de 100\%, em que a maioria das vezes não se chega ao mínimo do esperado, devido à estrutura precária do sistema que gerencia as políticas educacionais. Para implantar e manter uma sala de recursos multifuncional com recursos federais é preciso perceber se realmente as parcerias acontecem de forma satisfatória, com uma gestão que assuma seus compromissos com a esfera pública.

Segundo Pletsch (2010), nos discursos veiculados sobre financiamento da educação inclusiva vem se propagando como recursos suficientes, incumbindo ao Estado administrar da melhor forma possível, basta articular a sociedade no sentido do voluntarismo cívico.

Com essas medidas, é reduzido o recurso público para a educação em todas as áreas, comprometendo radicalmente a qualidade do ensino. Para Pletsch (2010) "o percentual de 3,5\% do PIB não apenas é insuficiente para as necessidades educacionais reais do país, como, frequentemente sequer é cumprido.”( p. 57).

Um ponto a ser destacado refere-se à implementação de uma política de educação inclusiva fora dos espaços urbanos como é o caso de comunidades ribeirinhas, quilombolas, indígenas e outros, sem fazer um estudo prévio para conhecer a realidade e necessidade de cada local. Pois, de acordo com Oliveira (2015) implantar uma SRM no meio da Amazônia é um tanto contraditório devido às especificidades das populações que, na maioria dos casos, não possuem um aparato adequado (necessário para suportar a estrutura tecnológica) para o funcionamento, as questões de melhoria de infraestrutura deveriam ser prioridades. Ações desta natureza contribuem para o gasto público na aquisição de materiais fadados ao desuso e empilhamento em salas de recursos multifuncionais.

A estratégia 4.26 aprofunda mais o debate sobre a desresponsabilização do município no que concerne a inclusão do aluno com deficiência na escola, ao focar sobre 
Políticas dE EDUCAÇÃo ESPECIAL: ANÁLISE DO PLANO DE EDUCAÇÃo (2015 - 2025) E DIRETRIZES DA EDUCAÇÃO ESPECIAL (2012) DE MACAPÁ-AP

o acesso e permanência no que permitir, ou seja, no que for possível que as salas de aula regular ofereçam condições de permanência e aprendizagem para todos, atendendo um número máximo de 25 alunos incluindo os alunos com deficiência (MACAPÁ, 2015).

Neste sentido, garantir acesso e permanência com qualidade para todos dentro de um sistema que se mantem pela via da exclusão fica comprometido, visto que as políticas educacionais não garantem o desenvolvimento pleno dos alunos, sejam eles com ou sem deficiência. Dentro desta lógica, expressões inconclusas mantem um cenário de descompromissos e distante da participação popular no engajamento por uma inclusão escolar efetivamente real. Garcia (2004) adota a compreensão:

Segundo a qual INCLUSÃO consiste na relação travada em contexto histórico-social, por sujeitos sociais, ou seja, uma prática complexa e contraditória, com sentido de luta, de embate, que convive necessariamente com seu contrário - a exclusão -, mas que se estabelece na direção de questionar e superar práticas sociais baseadas na desigualdade (GARCIA, 2004. p. 02, grifo nosso).

Não obstante, faz-se necessário desenvolver uma análise das políticas de inclusão no contexto de suas conjecturas, não evidenciando apenas como ações ou medidas, mas como objeto de contestação, como um processo fruto de discussões (GARCIA, 2004). Rompendo com o discurso de que as políticas educacionais não se materializam na prática, Fairclough (2001) enfatiza que na atual estrutura política neoliberal, os discursos já são práticas que se põem sob suas próprias concepções.

\subsection{Diretrizes para a Educação Especial de Macapá (2012) e a concepção de deficiência intelectual}

De acordo com Shiroma, Campos e Garcia (2005) é necessário interpretar os textos e suas entrelinhas para poder compreender as políticas públicas. Os discursos propagados no corpo dos textos estão carregados de conceitos e concepções contraditórias, visto que, a estrutura da linguagem mostra incompreensões, fragmentação com 
foco fora da realidade ao qual estão sendo aplicadas tais políticas. Deste modo, quando se analisa um documento que determina os caminhos da educação de determinado grupo de alunos, deve-se perceber de que forma essa política está concebendo tal alunado.

Segue esta mesma linha de análise os fundamentos que compõem o texto das Diretrizes para a Educação Especial no Município de Macapá (2012), pois apontam para a concretude das políticas sob a égide do capital, quando enfatizam que o sistema de ensino municipal deve se organizar de forma a assegurar "a igualdade de oportunidade, o respeito às diferenças e a valorização da diversidade no processo educativo" (MACAPÁ, 2012, p. 10).

Ao conceber esses valores como condição para Inclusão Escolar, está implícita a ideia de que a inclusão do aluno dependerá dele mesmo, visto que ao receber o tratamento igual, será negado as suas peculiaridades e necessidades básicas, desconsiderando as formas de aprender de cada um. Para Bakhtin (2006) "o discurso constitui uma superestrutura, visto que as relações entre linguagem e sociedade são colocadas sob o signo da dialética, enquanto efeito das estruturas sociais.”( p. 16).

Seguindo este mesmo raciocínio, foca-se para a concepção de deficiência intelectual contida na diretriz para a Educação Especial do Município de Macapá, que a conceitua como "limitações significativas no funcionamento intelectual e no comportamento adaptativo e está expresso nas habilidades práticas, sociais e conceituais, originando-se antes dos dezoito anos de idade" (Macapá, 2012, p. 44). Percebe-se claramente o enfoque clínico da deficiência e aponta a dificuldade de definir entre deficiência mental e intelectual, fortalecendo os estigmas sobre as pessoas com deficiência.

Segundo Pletsch (2010), a atual definição e classificação de deficiência mental apresentada pela Associação Americana de Retardo Mental - AAMR (2006), apesar de 
Políticas dE EDUCAÇÃo ESPECIAL: ANÁLISE DO PLANO DE EDUCAÇÃo (2015 - 2025) E DIRETRIZES DA EDUCAÇÃO ESPECIAL (2012) DE MACAPÁ-AP

suas várias reformulações ao longo da história, ainda estigmatiza e é usada erroneamente como resultado global a respeito de seres humanos complexos. Mesmo com uma nova terminologia é preciso lembrar que a definição de deficiência intelectual continua tendo como base o conceito de deficiência mental da AAMR (PLETSCH, 2010), o qual está presente no documento que norteia os caminhos da Educação Especial do Município de Macapá.

Contrapondo ao modelo clínico, o enfoque social sobre a deficiência considera que este sujeito deve ser visto na sua totalidade, ou seja, na sua condição bio-psicosocial (VYGOTSKY, 1997). Para este autor, as deficiências são definidas em primárias e secundárias. A primária se refere a sua condição biológica, causada por questões genéticas ou hereditárias, já a deficiência secundária é aquela definida pelo meio social ao qual o individuo está inserido, ocasionando as barreiras para o desenvolvimento das funções psicológicas superiores. Em outras palavras, são as "funções psíquicas superiores, o produto do desenvolvimento histórico dos humanos" (Vygotsky, 2001, p. 64). Aponta ainda, que as barreiras impostas pelo social são fatores que geram as deficiências secundárias.

Desse modo, as relações sociais, tanto na família como na escola e outros setores da sociedade, assim como a formulação de políticas e gerenciamento adequado devem contribuir de forma significativa para o desenvolvimento das pessoas com deficiência. Caso contrário, as mesmas ficarão à margem dos processos de aprendizagem e de adquirirem consciência para administrar com autonomia suas vidas.

Outro ponto de análise da Diretriz está no discurso fidedigno das políticas e dispositivos legais nacionais que seguem as bases internacionais, confirmando o discurso das políticas neoliberais, que nas últimas décadas sustentam os instrumentos que direcionam a educação especial nos municípios brasileiros. Um projeto maior de inclusão está em vigor e a tendência é que os partícipes estejam no mesmo caminho como 
forma de atender aos organismos que determinam os destinos dos países pobres ou em desenvolvimento.

Sendo assim, este se constitui como um instrumento que flutua nas contradições emergindo no meio social como fator ideológico. "A ideologia se monta como reflexo das estruturas sociais, onde toda tendência ideológica encadeia uma modificação no discurso" (BAKHTIN, 2006, p. 16). Na análise de Shiroma, Campos e Garcia (2005), a hegemonia discursiva aponta uma tendência crescente da homogeneização das políticas em nível mundial. Constituindo-se de elementos dos contextos das políticas internacionais que apontam medidas exitosas, isso permite compreender a natureza destas ações que são recomendadas aos países subdesenvolvidos.

A partir da concepção de deficiência intelectual, existente na Diretriz para a Educação Especial do município em estudo, analisa-se de que forma é vista a avaliação da aprendizagem no processo de inclusão. É conceituada como "processual, diagnóstica, formativa, participativa e cumulativa" (MACAPÁ, 2012, p. 61). E faz referência a avaliação diagnóstica, por permitir a "mediação por parte do professor na Zona de Desenvolvimento Proximal do aluno” (MACAPÁ, 2012, p. 62).

Segundo Prieto (2006), os avanços são inegáveis para o campo da Educação Especial, porém, o resultado das avaliações tem demostrado que a aprendizagem dos alunos está aquém do esperado. Para a autora é preciso cumprir com os objetivos estabelecidos na CF de 1988 para a educação, sendo um dos principais a "erradicação do analfabetismo, universalização do atendimento escolar, melhoria da qualidade de ensino, formação para o trabalho e promoção humanística, científica e tecnológica do país" (PRIETO, 2006, p. 50).

É fato que a política educacional brasileira tem deslocado de maneira progressiva para os municípios parte da responsabilidade administrativa, financeira e pedagógica pelo acesso e permanência de alunos com deficiência em decorrência do processo 
Políticas de educaÇão especial: ANÁLise do Plano de EDUCAÇão (2015 - 2025) E DIRETRIZES DA EDUCAÇÃO ESPECIAL (2012) DE MACAPÁ-AP

de municipalização do ensino fundamental. Assim, os municípios se organizam de acordo com planos e diretrizes formulados para estruturar e determinar o funcionamento das ações. Para Prieto (2006) o que se espera destes documentos é que eles sejam capazes de apontar propostas claras que favoreçam a aprendizagem e desenvolvimento de todo o seu alunado.

\section{Considerações finais}

Nas análises do discurso realizadas nesta pesquisa documental, percebeu-se que as políticas implantadas para a Educação Especial seguem as determinações de documentos internacionais como forma de regular a educação nos países que utilizam do capital internacional, como é o caso do Brasil.

As políticas de inclusão em estudo se configuram como pontos de interpretação da realidade que se vivencia em torno da educação das pessoas com deficiência intelectual. Diante disso, torna-se relevante levantar questionamentos sobre o processo de aquisição do saber, visto que, ao longo dos processos inclusão escolar os alunos com deficiência sempre estiveram à margem. É fato que estas crianças estão adentrando nas escolas em idade certa, porém, não estão dando continuidade nos seus estudos de forma efetiva e com qualidade de aprendizagem.

Os discursos apresentados nas políticas, segundo Shiroma, Campos e Garcia (2005), focalizam afirmações sobre o mundo em que se vive, como também, pretendem oferecer representações únicas da realidade, e ainda "trazem soluções idealizadas para problemas diagnosticados" (SHIROMA; CAMPOS; GARCIA, 2005, p. 13). É como se as análises dos discursos funcionassem como instrumentos de regulação para camuflar o que não pode se tornar evidente.

Considerando que as políticas na perspectiva inclusiva apontam para um descompasso entre a realidade concreta das escolas e as políticas propostas, onde se tem 
uma visão idealizada de educação, de escola e de aluno (SOUZA; DAINEZ; MAGIOLINO, 2015), torna-se profundamente urgente lutar pela criação de políticas que realmente se preocupem com o desenvolvimento dos alunos, principalmente dos alunos com deficiência.

Não se pode negar que nos textos das políticas há a ideia, sim, de desenvolvimento. Entretanto, a lógica apresentada está sustentada nos índices de desenvolvimento humano (IDH) dentro da sustentabilidade do capital (SOUZA; DAINEZ; MAGIOLINO, 2015).

Desta forma, esta definição foge do ideal de homem propagado pela teoria histórico cultural do desenvolvimento ao qual esta pesquisa se referencia, na qual segundo Vygotsky (1997), o homem deve se constituir observando todos os aspectos de seu desenvolvimento na totalidade como ser bio-psico-social.

Neste sentido, os documentos oficiais que determinam o caminhar da educação dos alunos com deficiência devem contemplar um discurso onde favoreça um "intenso processo de trabalho coletivo, de constituição dos sujeitos e de produção de conhecimentos na trama das relações sociais e práticas escolares" (SOUZA; DAINEZ; MAGIOLINO, 2015, p. 03).

Diante do que foi dito sobre a análise dos discursos apresentados nos planos de educação e nas diretrizes para a Educação Especial do Município de Macapá, constatou-se que são projetos de educação inclusivos distintos e em constante disputa, tanto projeto hegemônico neoliberal de Inclusão escolar quanto aquele que é resultante das lutas dos movimentos sociais. Entretanto, sabe-se que como está posto nos documentos oficiais, hegemonicamente segue a lógica (princípios) do projeto neoliberal e ao enfoque médico da deficiência, ao atribuir a concretização da educação inclusiva exclusivamente a escola, a família e do próprio aluno como responsáveis pelas mudanças no processo de exclusão. 
Políticas dE EDUCAÇÃo ESPECIAL: ANÁLISE DO PLANO DE EDUCAÇÃo (2015 - 2025) E DIRETRIZES DA EDUCAÇ̃̃o ESPECIAL (2012) DE MACAPÁ-AP

Porém para além destas análises, o que deve ser considerado e ponderado é que da forma com está efetivada a educação de meninas e meninos com deficiência intelectual precisa ser repensada, avaliada, estudada, constituídas por políticas cujo foco deve incidir diretamente no aprendizado deste aluno, pensando no seu desenvolvimento pleno, consequentemente os planos e diretrizes dos municípios brasileiros devem ser propícios para uma educação eminentemente de qualidade. Tendo estes incluídos no todo do sistema escolar, aprendendo com qualquer criança que adentra na escola em idade certa.

\section{Nota:}

${ }^{1}$ A nova política da Educação Especial na Perspectiva Inclusiva (2008) define o público alvo da Educação Especial: alunos com deficiência, transtornos globais do desenvolvimento e altas habilidades/superdotação.

\section{Referências}

BAKHTIN, Mikhail. Marxismo e filosofia da linguagem. 12. ed. São Paulo: HUCITEC, 2006.

BRASIL. Constituição Federal de 1988, artigos 208 e 211. Constituição da República Federativa do Brasil. Disponível em: <http://www.planalto.gov.br/ccivil_03/constituicao/constituicao.htm>. Acesso em: 20 nov. 2016.

E.C. no 59/2009. Constituição Federal de 1988, artigo. 212. De 11 de novembro de 2009. Brasília-DF. Disponível em: $<$ http://www.planalto.gov.br/ccivil 03/constituicao/emendas/emc/emc59.htm $>$. Acesso em: 17 nov. 2016. 
. MEC. Lei de Diretrizes da Educação Básica Nacional- LDBEN - no 9.394/ 1996.

Brasília, 1996. Disponível em < http:/ /www.planalto.gov.br/cci-

vil_03/leis/L9394.htm>. Acesso em: 17 nov. 2016.

. MEC/SEESP. Marcos Politicos-Legais da Educação Especial na Perspectiva Inclu-

siva. p.72. Brasília: SEESP, 2010. < http://portal.mec.gov.br/index.php?op-

$\underline{\text { tion }}=\mathrm{com}$ docman\&view $=$ download $\&$ alias $=6726-$ marcos-politicos-legais $\& I t e-$

$\underline{\operatorname{mid}=30192}>$. Acesso em: 18 out. 2018.

BOROWSKY, Fabíola. A relação entre a educação pública e a privada na Educação Especial brasileira. In: PERONI, Vera (Org.) Redefinições das fronteiras entre o público e o privado: Implicações para a democratização da educação. Liber Livro. p, 308-326. Brasília, 2013.

CORRÊEA, Nesdete Mesquita; KASSAR, Mônica de Carvalho de Magalhães. Municipalização em tempos de Reforma do Estado: A Educação Especial em foco. Uberlândia, 2009. Disponível em <http://www.simposioestadopoliticas.ufu.br/imagens/anais/pdf/BC16>. Acesso em: 20 nov. 2016.

FAIRCLOUGH, N. Discurso e mudança social. Tradução: Izabel Magalhães. Brasília: UNB, 2001.

FARENZENA, Nalú; MACHADO, Maria Goreti Farias. O custo das escolas públicas municipais: resultados de uma pesquisa e implicações políticas. Revista Brasileira de Política e Administração da Educação. v. 22, n. 2, p. 277-290, jul./dez. 2006.

GARCIA, Rosalba Maria Cardoso. Discursos políticos sobre inclusão: questões para as políticas públicas de Educação Especial no Brasil. 27ª Reunião Anual da ANPEd. Caxambu, 2004. Disponível em: < http://27reuniao.anped.org.br/gt15/t1510.pdf>. Acesso em: 20 nov. 2017.

GIL, Juca et al. Gestão das políticas de atendimento aos alunos com necessidades educacionais especiais em municípios paulistas. In: Jornal de Políticas Educacionais. $\mathrm{N}^{\circ} 7$. Jan. - jun. 2010.

JANNUZZI, Gilberta. A educação do deficiente no Brasil: dos primórdios ao início do século XXI. 2. ed. Campinas, SP: Autores Associados, 2006. 
Políticas de educaÇão especial: ANÁLise do Plano de EDUCAÇão (2015 - 2025) E DIRETRIZES DA EDUCAÇ̃̃O ESPECIAL (2012) DE MACAPÁ-AP

KASSAR, Mônica de Carvalho Magalhães. Proposta de Educação Inclusiva: uma nova política? In: MARQUEZINE, Maria Cristina et al (Orgs.). Políticas Públicas e formação de recursos bumanos em Educação Especial. Londrina: ABPEE, 2009.

- Percursos da constituição de uma política brasileira de educação Especial inclusiva. Revista Brasileira da Educação Especial, Marília, v.17, no especial, p. 41-58, maio/ago. 2011. Disponível em: < http://www.scielo.br/scielo.php?script=sci arttext\&pid=S1413-65382011000400005\&lng $=$ pt\&nrm=iso\&tlng $=$ pt $>$

KASSAR, Mônica de Carvalho Magalhães; DE OLIVEIRA, Andrea Duarte; da SILVA, Giane Aparecida Moura. Inclusão em escolas municipais: análise inicial de um caso. Educaşão (UFSM), v. 32, n. 1, 2007. Disponível em:

< http://www.redalyc.org/pdf/1171/117117241009.pdf. >

MACAPÁ . P. M. M. Diretrižes para a Educaşão Especial . PMM/SEMED/DIEES, 2012. $(2015-2025)$.

. Lei n. 2.178/2015, PME/CMM, 2015. Plano Municipal de Educação de Macapá

OLIVEIRA, Ivanilde Apoluceno de. Políticas e práticas de inclusão de pessoas com deficiência na Amazônia paraense: um olhar a partir de produções acadêmicas. p. 54. In: ANJOS, Hildete Pereira dos (Org.). Olhando a educação como um direito: inclusão e diversidade. Belém: Paka-Tatu, 2015.

PERONI, Vera. Políticas educacionais e a relação público/privado. In: 32. ${ }^{a}$ Reunião Anual da ANPEd. Caxambu, MG, 2009.

PLETSCH, Márcia Denise. Repensando a inclusão escolar: diretrizes políticas, práticas curriculares e deficiência intelectual. Rio de Janeiro: Nau. Edur, 2010.

PRIETO, Rosângela Gavioli. Atendimento escolar de alunos com necessidades educacionais especiais: Um olhar sobre as políticas públicas de educação no Brasil. In: MANTOAN, Maria Teresa Eglér; PRIETRO, Rosângela Gavioli; ARANTES, Valéria Amorim (Orgs.). Inclusão escolar: Pontos e Contrapontos. São Paulo: Summus, 2006.

RABELO, Jackline; JIMENEZ, Susana; SEGUNDO, Maria das Dores Mendes (Org.). O movimento de Educação para todos e a crítica marxista. Fortaleza: Imprensa Universitária, 2015.

Cadernos de Pós-graduação, São Paulo, v. 17, n. 2, p. 197-221, jul./dez. 2018. 
SHIROMA, Eneida Oto; CAMPOS, Roselane Fátima; GARCIA, Rosalba Maria Cardoso. Decifrar textos para compreender a política: subsídios metodológicos para análise do documento. Florianópolis. v. 23, n. 02, p. 427- 446, jul./dez. 2005. Disponível em <http://www.ced.ufsc.br/nucleos/nup/perspectiva.html>. Acesso em: 21 nov. 2017.

SILVA, M. L; OLIVEIRA, M. Da reprodução à contraposição ao discurso hegemônico da política de formação docente: um estudo com os professores que atuam com alunos com síndrome de Down. In: ANJOS, Hildete Pereira dos (Org.). Olhando a Educaşão como um direito: inclusão e diversidade. Belém: Paka-Tatu, 2015.

SOUZA, D. B. de; FARIA, L. C. M de. Reforma do Estado, descentralização e municipalização do ensino no Brasil: a gestão política dos sistemas públicos de ensino pós LDB 9.394/96. Ensaio: avaliação e políticas públicas em educação, Rio de Janeiro, v.12, n. 45, p. 925-944, out./dez. 2004. < http://www.scielo.br/pdf/\%0D/ensaio/v12n45/v12n45a02.pdf>

SOUZA, F. F; DAINEZ, Debora; MAGIOLINO, L. L. S. Educação e Desenvolvimento Humano: modos de mediação e participação nos meandros das práticas educacionais inclusivas. In: PLETSCH, Márcia Denise; MENDES, Geovana Mendonça Lunardi; HOSTINS, Regina Célia Linhares (Orgs.). A escolarização de alunos com deficiência intelectual: políticas, práticas e processos cognitivos. p, 15-30. São Carlos: Marquezine \& Manzini: ABPEE, 2015.

VYGOTSKI, L.S. Obras Escogidas: Fundamentos da Defectologia. Vol. V. Madrid: Visor, 1997. 2001.

- A defectologia e o estudo do desenvolvimento e da educaşão da criança. Madrid: Visor,

recebido em 4 ago. 2017 / aprovado em 14 set. 2018

Para referenciar este texto:

SANTOS, M. M.; SILVA, M. C. L.; BARLETA, I. A. Políticas de educação especial: análise do plano de educação (2015 - 2025) e diretrizes da educação especial (2012) de Macapá-AP. Cadernos de Pós-graduação, São Paulo, v. 17, n.2, p. 197-221, jul./dez. 2018. Disponível em: $<$ https://doi.org/10.5585/cpg.v17n2.7647>. 